\title{
Insulin Response to Glucagon with or without Tolbutamide in Normal and Diabetic Subjects
}

\author{
Masamichi Chiba, Akira Ohneda, Takeaki Sakai and \\ Yoshio Goto \\ The Third Department of Internal Medicine, Tohoku Univeristy \\ School of Medicine, Sendai 980
}

\begin{abstract}
Chiba, M., Ohneda, A., Sakai, T. and Goto, Y. Insulin Response to Glucagon with or without Tolbutamide in Normal and Diabetic Subjects. Tohoku J. exp. Med., 1982, $136(2), 169-175$ _ In order to investigate insulin response to glucagon, eight normal subjects and thirty diabetic patients were studied. According to fasting blocd glucose, diabetic patients were classified into three groups; mild, moderate and severe. An oral glucose tolerance test, a glucagon test and a tolbutamide-glucagon test were performed at intervals of several days. In the glucose tolerance test, insulin response was reduced in the patients with moderate or severe diabetes. Plasma insulin increased and reached a peak $3 \mathrm{~min}$ after glucagon injection (glucagon 1) in the normal controls $(66.1 \pm 9.9 \mu \mathrm{U} / \mathrm{ml}$ ), while plasma insulin response to glucagon 1 was reduced in the three diabetic groups $(35.8$ $\pm 7.3, \quad 33.2 \pm 9.7$ and $22.9 \pm 5.0 \mu \mathrm{U} / \mathrm{ml}$, respectively). In the normal subjects glucagon injected $60 \mathrm{~min}$ after tolbutamide (glucagon 2) caused a rise in insulin $(72.0 \pm 4.9 \mu \mathrm{U} / \mathrm{ml})$. In the diabetic groups, glucagon 2 caused a reduced response of plasma insulin $(38.6 \pm 8.9,49.5 \pm 17.4$ and $34.8 \pm 11.3 \mu \mathrm{U} / \mathrm{ml}$, respectively). Glucagon with or without tolbutamide produced a far greater maximal response of plasma insulin in all the diabetic groups than in the normal subjects, while glucose produced a not significantly different increment of plasma insulin between the normal subjects and the mild diabetics. The present study demonstrates the glucagon injection with or without tolbutamide could clearly discriminate the insulin response in diabetics from that in normal subjects. glucagon test insulin response; glucose tolerance test; glucagon test; tolbutamide-
\end{abstract}

Glucose tolerance test has been clinically and widely used, in order to investigate insulin response in diabetes mellitus. However, it is difficult to discriminate diabetics from the normal subjects in view of insulin levels. In 1974, it was reported from our laboratory that the plasma insulin level $30 \mathrm{~min}$ after glucose load was significantly decreased in diabetes mellitus compared with the normal controls when glucose was given $60 \mathrm{~min}$ after tolbutamide injection (Ohneda et al. 1974). Furthermore, we reported preliminarily a decrease in the maximal insulin response in a few cases of diabetes mellitus when glucagon was administered $60 \mathrm{~min}$ after tolbutamide injection (Ohneda et al. 1975). Therefore, the present study was undertaken in order to investigate the responses of plasma

Received for publication, March 17, 1981. 
insulin to glucagon with or without tolbutamide and to compare those to glucose in normal and diabetic subjects.

\section{SubJects and Methods}

In this study, eight healthy students and 30 diabetic subjects were investigated. The age of the subjects ranged from 29 to 69 years. In each group, an oral glucose tolerance test (GTT) was followed by an intravenous glucagon test (GT) and a tolbutamide-glucagon test (TGT) at intervals of several days. In GTT, $50 \mathrm{~g}$ glu cose was administered orally after an overnight fast and blood samples were drawn at 30 min intervals for $2 \mathrm{hr}$, as described previously (Goto et al. 1960). In GT, after two baseline samples were drawn, $1 \mathrm{mg}$ of glucagon dissolved in $1 \mathrm{ml}$ of saline solution, which was donated by Novo Institute, was injected into the cubital vein within 10 sec and blood samples were obtained from the antecubital vein at the other side at $1,3,6,10,15,20,30,45,60,90$ and $120 \mathrm{~min}$.

In TGT, after two base line samples were drawn, $1 \mathrm{~g}$ tolbutamide in $5 \%$ solution (Rastinon, Hoechst Japan) was injected into the antecubital vein for $2 \mathrm{~min}$ and blood samples were drawn 3,6,10,20,30,45 and $60 \mathrm{~min}$ after the start of the injection. Just. after drawing blood samples at $60 \mathrm{~min}, 1 \mathrm{mg}$ of glucagon was injected intravenously and blood samples were obtained at the same protocol as in GT.

A diagnosis for diabetes mellitus was made by the recommendation of Japan Diabetic Society (Kuzuya 1970).

Thirty diabetic patients were divided into three groups according to the fasting levels of blood glucose, mild, moderate and severe diabetes mellitus. The mild diabetes (10) was classified by the fasting blood glucose lower than $120 \mathrm{mg} / 100 \mathrm{ml}$, moderate diabetes (10) between 120 and $200 \mathrm{mg} / 100 \mathrm{ml}$ and severe diabetes (10) higher than $200 \mathrm{mg} / 100$ $\mathrm{ml}$.

Capillary blood was obtained from the ear lobe and blood glucose was determined by the glucose oxidase method (Teller 1956). Blood obtained from the antecubital vein into the heparinized syringes was poured into the glass tubes chilled in an ice box. The blood was centrifuged immediately after the completion of the test and plasma was stored at $-20^{\circ} \mathrm{C}$ until assay. Plasma insulin was determined by the Morgan-Lazarow method (1962).

Data in the study are presented as the mean \pm s.E. and the statistical analyses were performed by Student's $t$ test.

\section{Results}

\section{Glucose tolerance test}

The mean levels of blood glucose and plasma insulin during GTT in the normal subjects and the diabetic patients are presented in Fig. 1. In the normal controls, blood glucose rose from the fasting level of $87.4 \pm 1.8 \mathrm{mg} / 100 \mathrm{ml}$ and reached a peak of $152.4 \pm 4.1 \mathrm{mg} / 100 \mathrm{ml}$ at $30 \mathrm{~min}$. Then blood glucose fell to the initial level at 120 min. Plasma insulin during GTT in the normal subjects increased from the fasting level of $7.5 \pm 1.3 \mathrm{U} / \mathrm{ml}$ and reached a peak level of $64.9 \pm 12.6 \mathrm{U} / \mathrm{ml}$ at $60 \mathrm{~min}$, returning to the initial level at $120 \mathrm{~min}$.

The fasting level of blood glucose in the mild, moderate and severe diabetics were $105.1 \pm 2.4,155.4 \pm 4.0$ and $220.1 \pm 11.4 \mathrm{mg} / 100 \mathrm{ml}$, respectively. Blood glucose after oral glucose load was $228.9 \pm 13.4$ at $60 \mathrm{~min}$ in mild diabetes, $310.0 \pm 11.6$ at $90 \mathrm{~min}$ in moderate diabetes and $369.7 \pm 14.2 \mathrm{mg} / 100 \mathrm{ml}$ at $90 \mathrm{~min}$ in severe diabetes.

Insulin response to glucose was reduced in the diabetics, as glucose tolerance 

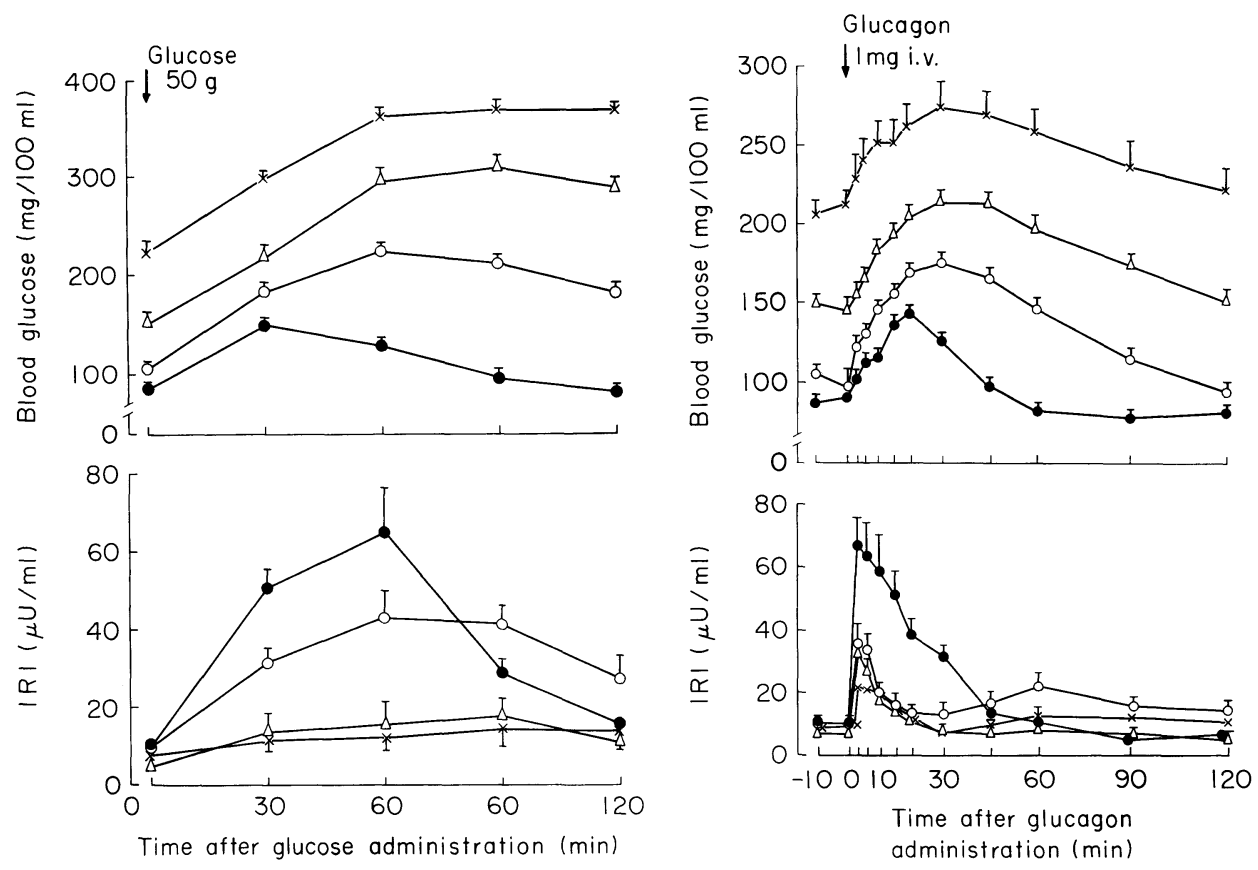

Fig. 1

Fig. 2

Fig. 1. Blood glucose and plasma insulin during the oral glucose tolerance test in normal and diabetic subjects (mean \pm s.e.). $--\bullet$, normal subjects $(N=8)$; ○-०, mild diabetes $(N=10) ; \Delta-\Delta$, moderate diabetes $(N=10) ; \times-\times$, severe diabetes $(N=10)$.

Fig. 2. Blood glucose and plasma insulin during the intravenous glucagon test in normal and diabetic subjects (mean \pm s.e.). $-\cdots$, normal subject $(N=8)$; $\bigcirc-\circ$, mild diabetes $(N=10) ; \Delta-\Delta$, moderate diabetes $(N=10) ; \times-\times$, severe diabetes $(N=10)$.

was decreased. The fasting levels of plasma insulin in the mild, moderate and severe diabetics were $9.8 \pm 1.7,5.3 \pm 1.0$ and $8.2 \pm 2.6 \mu \mathrm{U} / \mathrm{ml}$, respectively. The maximal levels of plasma insulin during GTT were $42.2 \pm 7.2 \mu \mathrm{U} / \mathrm{ml}$ in mild diabetes, $18.2 \pm 3.4 \mathrm{U} / \mathrm{ml}$ in moderate diabetes and $14.9 \pm 4.4 \mu \mathrm{U} / \mathrm{ml}$ in severe diabetes.

The maximal increment of plasma insulin was $55.5 \pm 13.0 \mu \mathrm{U} / \mathrm{ml}$ in the normal subjects and those in mild, moderate and severe diabetes were $39.1 \pm 7.9,16.4 \pm 4.3$ and $9.4 \pm 2.7 \mu \mathrm{U} / \mathrm{ml}$, respectively.

\section{Glucagon test}

The changes in blood glucose and plasma insulin after the intravenous injection of glucagon are shown in Fig. 2. Blood glucose rose from the fasting level of $91.4 \pm 1.2 \mathrm{mg} / 100 \mathrm{ml}$ to a peak level of $143.9 \pm 2.2 \mathrm{mg} / 100 \mathrm{ml}$ at $20 \mathrm{~min}$ after glucagon injection in the normal subjects, returning to the initial level at $45 \mathrm{~min}$. Plasma insulin rose from the base line level of $6.6 \pm 1.6 \mu \mathrm{U} / \mathrm{ml}$ and reached a peak level of $66.1 \pm 9.9 \mu \mathrm{U} / \mathrm{ml}$ at $3 \mathrm{~min}$.

In three groups of the diabetics, blood glucose rose after the glucagon injection and reached a peak later than in the normal subjects. In addition, response of 
plsma insulin to glucagon was reduced in all the diabetic groups. In mild diabetes, blood glucose rose from the fasting level of $97.6 \pm 9.2$ and reached a peak level of $174.9 \pm 7.3 \mathrm{mg} / 100 \mathrm{ml}$ at $30 \mathrm{~min}$. Plasma insulin increased from the fasting level of $9.9 \pm 1.8 \mu \mathrm{U} / \mathrm{ml}$ to a peak of $35.8 \pm 7.3 \mu \mathrm{U} / \mathrm{ml}$ at $3 \mathrm{~min}$. In moderate diabetes, blood glucose rose from the base line of $146.4 \pm 4.6$ to a peak of $214.3 \pm 6.1 \mathrm{mg} / 100$

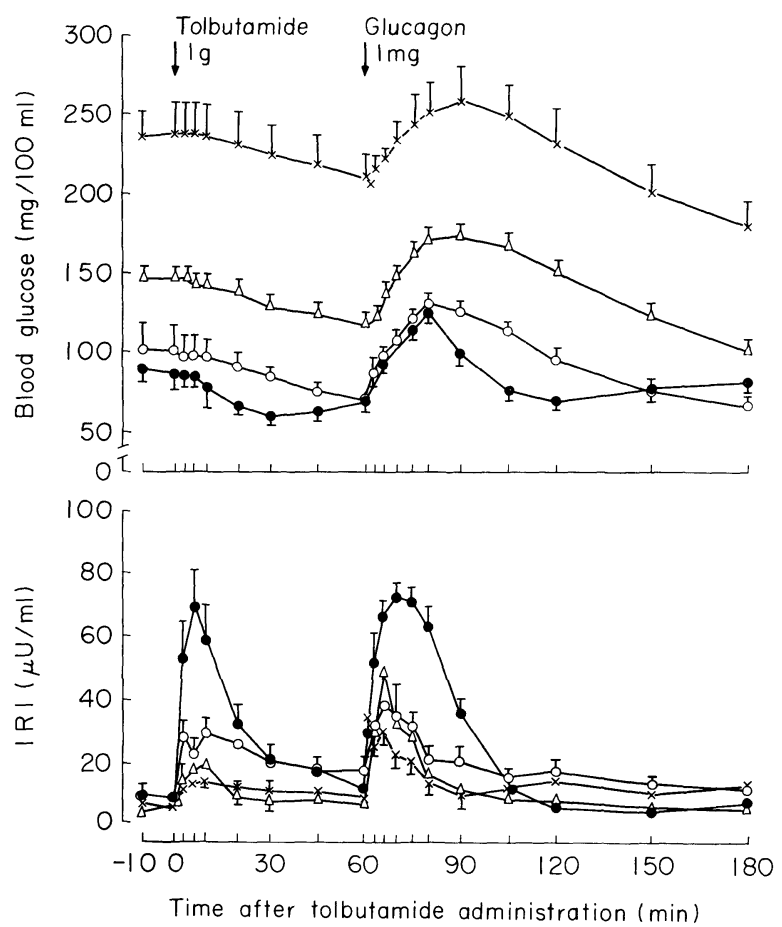

Fig. 3. Blood glucose and plasma insulin after tolbutamide followed by glucagon in normal and diabetic subjects (mean \pm s.E.). $-\bullet$, normal subjects $(N=8)$; $0-0$, mild diabetes $(N=10) ; \Delta-\Delta$, moderate diabetes $(N=10) ; \times-\times$, severe diabetes $(N=10)$.

$\mathrm{ml}$ at $30 \mathrm{~min}$. Plasma insulin increased from the base line level of $8.5 \pm 1.8 \mu \mathrm{U} / \mathrm{ml}$ to a peak level of $33.2 \pm 9.6 \mathrm{U} / \mathrm{ml}$ at $3 \mathrm{~min}$. In severe diabetes, blood glucose rose from the fasting level of $212.7 \pm 14.7 \mathrm{mg} / 100 \mathrm{ml}$ to a peak level of $261.7 \pm 15.6 \mathrm{mg} /$ $100 \mathrm{ml}$. The increase in plasma insulin was minimum in the group of severe diabetes, the peak insulin level showing $22.9 \pm 5.0 \mu \mathrm{U} / \mathrm{ml}$ at $3 \mathrm{~min}$.

\section{Tolbutamide-glucagon test}

The changes in blood glucose and plasma insulin in TGT are shown in Fig. 3. In the normal controls, blood glucose decreased from the fasting level of $87.9 \pm 2.7$ $\mathrm{mg} / 100 \mathrm{~m}$ to the nadir of $58.4 \pm 3.2 \mathrm{mg} / 100 \mathrm{ml}$ at $30 \mathrm{~min}$ after tolbutamide injection. Plasma insulin rose from the fasting level of $6.3 \pm 0.7 \mu \mathrm{U} / \mathrm{ml}$ to a peak of $69.4 \pm 13.1$ $\mu \mathrm{U} / \mathrm{ml}$ at $6 \mathrm{~min}$, and then fell to the initial level at $60 \mathrm{~min}$. After $1 \mathrm{mg}$ of glucagon was injected at $60 \mathrm{~min}$, blood glucose rose from the preinjection level of $76.1 \pm 5.7$ 
$\mathrm{mg} / 100 \mathrm{ml}$ to a peak of $125.8 \pm 2.8 \mathrm{mg} / 100 \mathrm{ml}$ at $80 \mathrm{~min}$ and returned to the initial level at $105 \mathrm{~min}$. Plasma insulin rose after glucagon injection from the initial level of $10.4 \pm 0.6 \mu \mathrm{U} / \mathrm{ml}$ to the peak level of $72.0 \pm 4.9 \mathrm{U} / \mathrm{ml}$ at $70 \mathrm{~min}$.

In these three diabetic groups, blood glucose continued to fall gradually until the time of $60 \mathrm{~min}$ after the tolbutamide injection, and the glucagon injection induced the same increment of blood glucose as that in the normal controls. In mild diabetes, blood glucose decreased from the fasting level of $104.8 \pm 4.2$ to the nadir of $71.8 \pm 3.9 \mathrm{mg} / 100 \mathrm{ml}$ at $60 \mathrm{~min}$. After the glucagon injection blood glucose rose and reached a peak of $131.8 \pm 4.4 \mathrm{mg} / 100 \mathrm{ml}$ at $80 \mathrm{~min}$. In moderate diabetes, blood glucose fell from the fasting level of $148.0 \pm 3.0$ to the level of 120.0 $\pm 3.5 \mathrm{mg} / 100 \mathrm{ml}$ at $60 \mathrm{~min}$. Blood glucose increased to a peak of $164.8 \pm 2.4 \mathrm{mg} /$ $100 \mathrm{ml}$ at $75 \mathrm{~min}$ after the glucagon injection. In severe diabetes, blood glucose decreased from the fasting level of $239.7 \pm 20.9$ to the nadir of $210.1 \pm 18.2 \mathrm{mg} / 100$ $\mathrm{ml}$ at $60 \mathrm{~min}$. After the glucagon injection blood glucose rose and reached 260.2 $\pm 22.9 \mathrm{mg} / 100 \mathrm{ml}$ at $90 \mathrm{~min}$.

The responses of plasma insulin to either tolbutamide or glucagon were lowered remarkably in the three diabetic groups. The maximal levels of plasma insulin after tolbutamide injection in mild, moderate and severe diabetes were 29.5 $\pm 3.6,19.7 \pm 4.7$ and $13.8 \pm 2.4 \mu \mathrm{U} / \mathrm{ml}$, respectively. The increments of plasma insulin after glucagon were also markedly reduced in all the diabetic groups, compared with the normal subjects. The maximal levels of plasma insulin in mild, moderate and severe diabetes were $38.6 \pm 8.9,49.5 \pm 17.4$ and $34.8 \pm 11.3 \mu \mathrm{U} / \mathrm{ml}$, respectively.

Comparison of maximal response of insulin to various stimuli

The maximal responses of plasma insulin to various stimuli in the normal subjects and the diabetic patients are shown in Fig. 4. The maximal insulin response to glucose decreased in all the diabetic groups but a significant difference

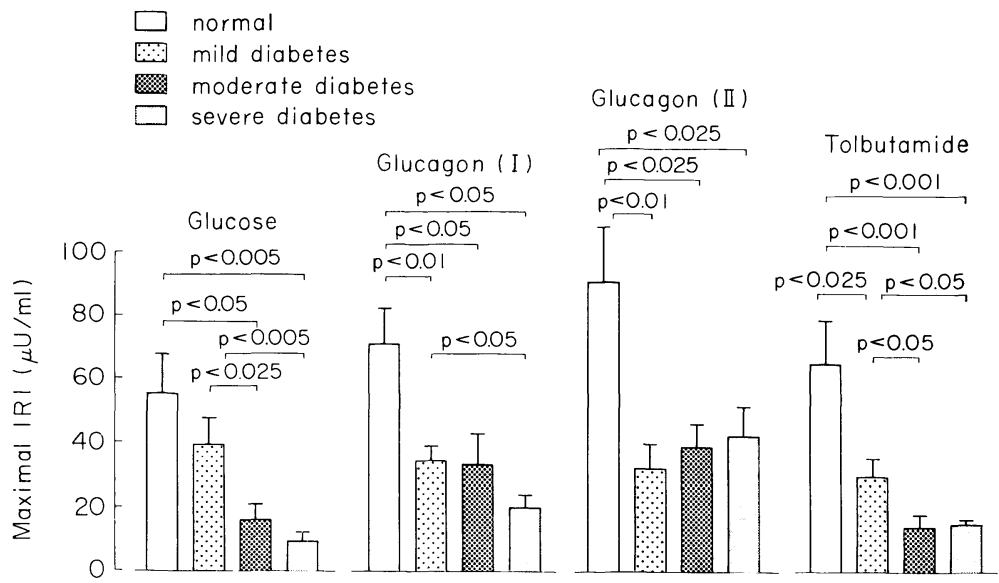

Fig. 4. Comparison of maximal insulin increment after glucose glucagon or tolbutamide in normal and diabetic subjects (mean \pm s.E.). 
was observed only in moderate and severe diabetes in comparison with the normal subjects $(p<0.05$ and $p<0.05$, respectively).

The maximal levels of plasma insulin after a single injection of glucagon (Glucagon I) decreased significantly in all the diabetic groups compared with the normal controls $(p<0.05$ at largest). The maximal levels of plasma insulin after the glucagon injection in TGT (Glucagon II) were also significantly decreased in all the diabetic groups ( $p<0.025$ or less).

The maximal levels of plasma insulin after the tolbutamide injection were reduced significantly in all the diabetic groups compared with the normal subjects $(p<0.025$ or less).

\section{Discussion}

Since the immunoassay for insulin was introduced, various stimuli have been proved to promote insulin secretion. However, there is no definite difference between normal subjects and diabetic patients as far as the fasting level of plasma insulin is concerned (Yalow and Berson 1960; Ohneda 1966). In order to discriminate diabetics from normal subjects, various stimuli including glucose have been employed. Insulin response to glucose, however, is not differentiated between normal and diabetic subjects (Yalow and Berson 1960). This is true even when the maximal insulin level and insulinogenic index during glucose tolerance test are compared (Sato 1974).

In the present study, it was observed that the injection of $1 \mathrm{mg}$ of glucagon caused the same increment of plasma insulin as in oral glucose load or tolbutamide injection in the normal subjects. However, the mode of insulin response to glucagon differs from that of the response to other stimuli in diabetic patients. In general, glucagon injection, especially with tolbutamide, induced a larger increment of the plasma insulin than oral glucose load or tolbutamide injection, although this difference was not significant.

As far as the maximal insulin response is concerned, glucose load could not discriminate the mild diabetes from the normal subjects, whereas glucagon (with or without tolbutamide) or tolbutamide could do.

Therefore, glucagon I, glucagon II or tolbutamide is superior to oral glucose in view of the response of plasma insulin in normal and diabetic subjects.

Ryan et al. (1967) proposed the intensive stimulation of B cell of the pancreatic islet, in which $1 \mathrm{mg}$ glucagon and $0.5 \mathrm{~g}$ tolbutamide were injected $30 \mathrm{~min}$ after oral glucose load. According to their study, an excessive response of plasma insulin was observed in mild diabetes, whereas severe diabetics showed a decreased response. In the test proposed by Ryan et al., glucagon and tolbutamide promote insulin secretion from the $B$ cells in the pancreas, where the synthesis and secretion of insulin are elevated by glucose administered previously. Therefore, their method elucidates the maximal intensive stimulation in both synthesis and release.

To the contrary, the tolbutamide-glucagon test, shown in the present study, consists of the enhanced release of insulin by tolbutamide and glucagon and would elicit the insulin reservior in the $B$ cells. 
At any rate, the present study demonstrates that glucagon with or without tolbutamide could clearly discriminate the insulin response in diabetics from that in normal subjects. Therefore glucagon is a useful tool in the investigation of insulin response in man.

\section{References}

1) Goto, Y., Kato, J., Takanami, A. \& Ohneda, A. (1960) Detection of prediabetes by glucose tolerance test sensitized by prednisolone. Lancet, 2, 461-464.

2) Kuzuya, N. (1970) Recommendation for the criteria of glucose tolerance test for the diagnosis of diabetes mellitus. J. Jap. Diabet. Soc., 13, 1-7. (Japanese)

3) Morgan, C.R. \& Lazarow, A. (1962) Immunoassay of insulin using a two-antibody system. Proc. Soc. exp. Biol. Med. (N.Y.), 110, 29-32.

4) Ohneda, A. (1966) Plasma insulin in normal and pathologic states. J. Jap. Diabet. Soc. 9, 353-357. (Japanese)

5) Ohneda, A., Sato, M. \& Yamagata, S. (1974) Insulin response to tolbutamide-glucose load in normal and diabetic subjects. Tohoku J. exp. Med., 116, 103-110.

6) Ohneda, A., Matsuda, K., Chiba, M., Iimura, Y. \& Yamagata, S. (1975) Glucagoninduced insulin secretion in normal and diabetic subjects. Tohoku J. exp. Med., 116, 103110.

7) Ryan, W.G., Nibbe, A.F. \& Schwartz, T.B. (1967) Beta-cytotrophic effects of glucose, glucagon, and tolbutamide in man. Lancet, 1, 1255-1256.

8) Sato, M. (1974) Study on the pathogenesis of diabetes mellitus in view of insulin response to glucose in man. Fol. endocr. jap., 50, 1101-1114. (Japanese)

9) Teller, J.D. (1956) Direct, quantitative colorimetric determination of serum or plasma glucose. In: Abstracts of Papers, 130th Meeting, Amer. Chem. Soc., p. 69C.

10) Yalow, R.S. \& Berson, S.A. (1960) Plasma insulin concentrations in non-diabetic and early diabetic subjects. Determination by a new sensitive immunoassay technic. Diabetes, 9, 254-260. 